\title{
TIPO DE MINIESTACA E DE SUBSTRATO NA PROPAGAÇÃO VEGETATIVA DE ANGICO-VERMELHO (Anadenanthera macrocarpa (Benth.) Brenan)
}

\author{
TYPE OF MINI-CUTTING AND SUBSTRATE ON VEGETATIVE PROPAGATION OF \\ ANGICO-VERMELHO (Anadenanthera macrocarpa (Benth.) Brenan)
}

\author{
Poliana Coqueiro Dias ${ }^{1}$ Aloisio Xavier ${ }^{2}$ Leandro Silva de Oliveira ${ }^{3}$ Anne Caroline Guieiro Correia ${ }^{4}$ \\ Giovani André Barbosa ${ }^{5}$
}

\begin{abstract}
RESUMO
O presente trabalho teve o objetivo de avaliar o efeito da redução da área foliar de miniestacas apicais e intermediárias e de diferentes substratos (vermiculita e composto orgânico) no enraizamento de seis progênies de meios-irmãos de Anadenanthera macrocarpa a partir de minicepas de origem seminal. As avaliações foram realizadas na saída da casa de vegetação (30 dias) e da casa de sombra (40 dias) para sobrevivência e exposição de raízes na extremidade inferior do tubete. Na fase de crescimento a pleno sol, aos 70 dias após o estaqueamento, foi avaliado o percentual de sobrevivência, enraizamento, altura, diâmetro de colo, número de raízes e massa seca da parte aérea e da raiz das miniestacas enraizadas. Observou-se para tipo de substrato e tipo de miniestacas diferença entre as progênies quanto às características analisadas. $\mathrm{O}$ substrato à base de vermiculita proporcionou maiores médias quanto à sobrevivência, enraizamento, altura, diâmetro do colo e peso de massa seca de raiz. De modo geral, para sobrevivência, enraizamento, número de raízes e massa seca da parte aérea e da raiz constatou-se que, independentemente da progênie, a miniestaca apical com $10 \mathrm{~cm}$ de comprimento e com a folha inteira apresentou maiores médias. Portanto, utilizando a vermiculita como substrato as miniestacas apicais com $10 \mathrm{~cm}$ de comprimento e folha inteira mostraram-se mais adequadas à propagação vegetativa de material seminal de Anadenanthera macrocarpa por miniestaquia.
\end{abstract}

Palavras-chave: propagação de plantas; miniestaquia; enraizamento.

\section{ABSTRACT}

This paper aimed to evaluate the effect of leaf area reduction of apical and intermediate mini-cuttings and different substrates (vermiculite and organic substrate) on the rooting of six half-sib Anadenanthera macrocarpa progenies from mini-stumps of seminal origin. The evaluations were carried out in the greenhouse (30 days) and the shade house (40 days) for survival rate and roots percentage observed at the bottom of the container. Survival rate and rooting percentage, height, stem diameter, number of roots, and dry mass of shoot and roots of mini-cuttings were evaluated, in the full sunlight area, 70 days after staking. The results showed that are not differences between progenies for type of mini-cuttings and substrate to characteristics evaluated. The vermiculite substrate provided the best results for the survival rate, rooting

1 Engenheira Florestal, Dr $^{\mathrm{a}}$., Professora do Departamento de Ciências Vegetais, Universidade Federal Rural do Semiárido, Prédio de Fitotecnia, Campus Leste, Av. Francisco Mota, 572, Costa e Silva, CEP 59625-900, Mossoró (RN).policoqueiro@yahoo.com.br

2 Engenheiro Florestal, Dr., Professor Associado do Departamento de Engenharia Florestal, Universidade Federal de Viçosa, Av. Peter Henry Rolfs, s/n, Campus Universitário, CEP 36570-000, Viçosa (MG). xavier@ufv.br

3 Engenheiro Florestal, Doutorando em Recursos Florestais, Universidade Superior de Agricultura "Luiz de Queiroz", Rua Saldanha Marinho, 2391, Vila Independência, CEP 36418-395, Piracicaba (SP). leandroengflor@gmail.com

4 Engenheira Florestal, Mestre em Ciência Florestal, Universidade Federal de Viçosa, Av. Peter Henry Rolfs, s/n, Campus Universitário, CEP 36570-000, Viçosa (MG). aguieirocorreia@yahoo.com.br

5 Estudante do Curso de Engenharia Florestal, Universidade Federal de Viçosa, Av. Peter Henry Rolfs, s/n, Campus Universitário, CEP 36570-000, Viçosa (MG). giovani_juruaia@hotmail.com

Recebido para publicação em 18/01/2012 e aceito em 13/11/2013 
percentage, height, stem diameter and weight of dry roots. In general terms, apical mini-cuttings up to $10 \mathrm{~cm}$ in length and entire leaf had higher averages survival rate, rooting percentage, root number and dry weight of shoot and root. Therefore, using vermiculite as substrate, apical mini-cuttings up to $10 \mathrm{~cm}$ in length and entire leaf were more appropriate for vegetative propagation from seminal material of Anadenanthera macrocarpa by mini-cutting technique.

Keywords: plant propagation; mini-cutting technique; rooting.

\section{INTRODUÇÃO}

Ao longo dos anos, a floresta nativa vem sendo fornecedora de produtos madeireiros para o comércio tanto interno quanto externo e, com a falta de reposição das áreas exploradas, houve significativa diminuição da oferta, principalmente das espécies de maior interesse madeireiro. A preocupação com o abastecimento de matéria-prima para carvão e outros produtos derivados da madeira, assim como a obrigatoriedade da restauração florestal e as pressões ambientais em relação à perda de material genético de grande valor e importância econômica e ecológica, têm conduzido ao estudo de espécies nativas.

Entre as espécies nativas potenciais, destacase o angico-vermelho (Anadenanthera macrocarpa (Benth.) Brenan), uma árvore que apresenta madeira muito utilizada no mercado interno, especialmente pelo emprego na construção rural, civil e na produção de lenha e carvão (CARVALHO, 2003). Contudo, segundo esse autor, a produção comercial de mudas dessa espécie via seminífera ao longo do ano tem sido limitada em razão de as sementes apresentarem recalcitrância.

Diante desse fato, a propagação assexuada pode ser uma opção para a produção de mudas de angico-vermelho, sendo os estudos com métodos de propagação vegetativa para a espécie ainda bastante superficiais (SILVEIRA e PAULA, 1998; SANTOS, 2002; INOUE e PUTTON, 2007) para embasar a utilização em plantios comerciais. Entre as técnicas de propagação vegetativa, a miniestaquia destaca-se como método economicamente viável de produção de mudas clonais de Eucalyptus, que tem permitido a uniformização dos plantios, maximização dos ganhos em produtividade e qualidade da madeira, além de proporcionar alto porcentual de enraizamento (XAVIER et al., 2009), no entanto, em se tratando de outras essências florestais, principalmente as nativas brasileiras, são poucos os estudos. Na literatura, exemplos de aplicação da miniestaquia foram realizados com sucesso em
Ilex paraguariensis (WENDLING et al., 2007), Erythrina falcata (CUNHA et al., 2008), Toona ciliata (SOUZA et al., 2009), Sapium glandulatum (FERREIRA et al., 2010), Calophyllum brasiliense (SILVA et al., 2010), podendo ser aplicado na propagação vegetativa de outras espécies a exemplo do angico-vermelho.

Segundo Xavier et al. (2009), entre os fatores que exercem influência no enraizamento de miniestacas, estão o tipo de substrato e o tipo de miniestaca utilizado. De acordo com Fachinello et al. (2005), o tipo de estaca utilizado vai influenciar o enraizamento, devendo-se observar a presença e o número de folhas, que constituem fonte de auxinas e carboidratos importantes no processo de enraizamento (HARTMANN et al., 2011). Entretanto, as folhas podem, em alguns casos, prejudicar o enraizamento pela perda de água por transpiração e pela presença de compostos inibidores do enraizamento provindos da área foliar (ASSIS e TEIXEIRA, 1998).

Outro fator que pode influenciar o enraizamento é o substrato por ter como funções a sustentação das estacas durante 0 período de enraizamento e a aeração adequada ao desenvolvimento das raízes, bem como por proporcionar condições de umidade e nutrição para o crescimento do sistema radicial (XAVIER et al., 2009). O substrato ideal para o enraizamento depende da espécie, do tipo de estaca, da época, do sistema de propagação, do custo e da disponibilidade de seus componentes (HARTMANN et al., 2011). Segundo Xavier et al. (2009), diversas são as opções de tipos de substrato, sendo os mais comuns nos viveiros de produção de mudas a areia, turfa, a serragem semidecomposta, casca de arroz carbonizada, o composto orgânico, a terra de subsolo, as fibras de coco, vermiculita e a mistura entre eles.

Diante da importância do tipo de miniestaca e do substrato para o enraizamento, objetivou-se com o presente trabalho estudar o comportamento de tipos de miniestacas e substratos no enraizamento de progênies de meios-irmãos de angico-vermelho. 


\section{MATERIAL E MÉTODOS}

\section{Instalação e manejo do minijardim}

O material experimental foi constituído de sementes de seis progênies de meios-irmãos de angico-vermelho (Anadenanthera macrocarpa), fornecidos pela Sociedade de Investigação Florestal - SIF/UFV, sendo cada uma das progênies procedentes de um município da Zona da Mata Mineira (P1-Porto Firme, P12-Piranga, P17-Cajuri, P35-Santa Bárbara do Tugúrio, P45-Rio Pomba e P60-Guaraciaba). O estabelecimento do minijardim foi feito no Viveiro de Pesquisas do Departamento de Engenharia Florestal da Universidade Federal de Viçosa - UFV, no município de Viçosa - MG.

Conforme a técnica de miniestaquia descrita em Xavier et al. (2009), o minijardim foi constituído de minicepas, obtidas pela propagação via seminal de seis progênies de Anadenanthera macrocarpa. As mudas foram produzidas em tubetes plásticos de $55 \mathrm{~cm}^{3}$ de capacidade, contendo como substrato composto orgânico Bioplant ${ }^{\mathbb{R}}$, sendo adicionados 8 $\mathrm{kg}$ de superfosfato simples e $300 \mathrm{~g}$ de osmocote ${ }^{\circledR}$ (na formulação 16-06-10) por $\mathrm{m}^{3}$ de substrato. Foram semeadas três sementes por tubete, sendo o raleio (aos 30 dias) efetuado onde houve a germinação de mais de uma semente. Ao atingirem altura média de $15 \mathrm{~cm}$ (40 dias), as mudas foram transferidas para o canaletão de areia e, após 50 dias (período de adaptação e crescimento das mudas), tiveram seus ápices podados à altura de $10 \mathrm{~cm}$ da base, visando estimular a ocorrência de brotações nas minicepas, que forneceram as miniestacas para o estudo.

O minijardim foi estabelecido em sistema semi-hidrôponico utilizando canteiro suspenso, sob cobertura de plástico transparente de polietileno, sendo o canaletão composto por uma calha de cimento-amianto, com 7,5 m de comprimento e 0,8 $\mathrm{m}$ de largura, contendo no seu interior areia para a sustentação das minicepas. Foram utilizadas 96 minicepas por progênie, alocadas no espaçamento de $10 \times 10 \mathrm{~cm}$, com fertirrigação por gotejamento distribuída quatro vezes ao dia, em uma vazão total diária de $4 \mathrm{~L} \mathrm{~m}^{-2}$.

A solução nutritiva utilizada na fertirrigação foi constituída pelas seguintes concentrações dos sais: nitrato de cálcio $\left(0,920 \mathrm{~g} \mathrm{~L}^{-1}\right)$, cloreto de potássio $\left(0,240 \mathrm{~g} \mathrm{~L}^{-1}\right)$, nitrato de potássio $(0,140 \mathrm{~g}$ $\left.\mathrm{L}^{-1}\right)$, monoamônio fosfato $\left(0,096 \mathrm{~g} \mathrm{~L}^{-1}\right)$, sulfato de magnésio $\left(0,364 \mathrm{~g} \mathrm{~L}^{-1}\right)$, hidroferro $\left(0,040 \mathrm{~g} \mathrm{~L}^{-1}\right)$, ácido bórico $\left(2,800 \mathrm{mg} \mathrm{L}^{-1}\right)$, sulfato de zinco $(0,480$ $\left.\mathrm{mg} \mathrm{L}^{-1}\right)$, sulfato de manganês $\left(1,120 \mathrm{mg} \mathrm{L}^{-1}\right)$, sulfato de cobre $\left(0,100 \mathrm{mg} \mathrm{L}^{-1}\right)$ e molibidato de sódio $\left(0,040 \mathrm{mg} \mathrm{L}^{-1}\right)$. A condutividade elétrica da solução nutritiva foi mantida em $2,0 \mathrm{mS} \mathrm{m}^{-2}$, a $25^{\circ} \mathrm{C}$.

\section{Obtenção e enraizamento das miniestacas}

Em períodos regulares de 26 dias, as minicepas proporcionaram miniestacas com comprimento entre 5 e $10 \mathrm{~cm}$, contendo de um a dois pares de folhas. Imediatamente após coletadas e preparadas, as miniestacas foram estaqueadas em casa de vegetação climatizada (com umidade relativa do ar superior a $85 \%$ e temperatura média de $25^{\circ} \mathrm{C}$ ), utilizando como recipientes tubetes plásticos de $55 \mathrm{~cm}^{3}$ de capacidade. A adubação de base foi composta por $8 \mathrm{~kg} \mathrm{~m}^{-3}$ de superfosfato simples e $300 \mathrm{~g}$ de osmocote (NPK - 16-06-10) misturados ao substrato de enraizamento. $\mathrm{Na}$ saída da casa de vegetação, foi feita adubação de cobertura, aplicando-se $2 \mathrm{~mL}^{\text {muda }}{ }^{-1}$ de fosfato monoamônico $\left(2,0 \mathrm{~g} \mathrm{~L}^{-1}\right)$, e na saída da casa de sombra, foram aplicados $5 \mathrm{~mL}$ muda $^{-1}$ do formulado NPK (10-05-30) $\left(6 \mathrm{~g} \mathrm{~L}^{-1}\right)$.

\section{Efeito do substrato e do tipo de miniestacas}

Foram utilizados dois tipos de substratos, vermiculita e composto orgânico, e dois tipos de miniestacas, apical e intermediária, conforme item anterior, no enraizamento adventício das progênies de angico-vermelho, em delineamento de blocos ao acaso, em arranjo fatorial $2 \times 2 \times 6$, constituído dos dois tipos de miniestacas, dois tipos de substrato e seis progênies, com quatro repetições e 10 miniestacas por parcela.

As avaliações feitas na saída da casa de vegetação (40 dias) e da casa de sombra (50 dias) foram para sobrevivência e raízes observadas na extremidade inferior do tubete. Aos 80 dias de idade, foram avaliados o porcentual de sobrevivência, altura, o diâmetro de colo, número de raízes e a massa seca da parte aérea e da raiz das miniestacas enraizadas. Os dados foram avaliados por meio de análise de variância e teste de médias (Teste de Tukey a $5 \%$ de probabilidade), utilizando-se o software Estatística 8.0 (Statsoft Inc. 2008).

Para as avaliações, as miniestacas enraizadas estavam com raízes maiores ou iguais a $0,5 \mathrm{~cm}$, com emissão de brotações na parte 
aérea. Na contagem do número de raízes, foram observadas as raízes emitidas diretamente da base das miniestacas. Foi feita a medição da altura e do diâmetro de colo nas miniestacas com presença de raiz e de brotações, sendo a altura determinada com uma régua milimetrada a partir do nível do substrato até a ponta da última folha, e o diâmetro de colo foi determinado ao nível do substrato, por um paquímetro de precisão. Para a obtenção da massa seca, a parte aérea foi individualizada da parte radicular e mantida em estufa à temperatura de $55^{\circ} \mathrm{C}$ até peso constante.

\section{Efeito da redução foliar e do tipo de miniestacas}

A partir das minicepas, foram obtidas miniestacas com comprimento variando entre 5 e $10 \mathrm{~cm}$, constituindo os seguintes tipos: MA10: apical com $10 \mathrm{~cm}$ de comprimento, contendo de um a dois pares de folhas, reduzidas a $25 \%$ de seu tamanho original; MI5: intermediária, com $5 \mathrm{~cm}$ de comprimento, contendo de um a dois pares de folhas, reduzidas a $25 \%$ de seu tamanho original; MA5: apical com $5 \mathrm{~cm}$ de comprimento, contendo de um a dois pares de folhas, reduzidas a $25 \%$ de seu tamanho original; e MA10i: apical com $10 \mathrm{~cm}$ de comprimento e folha inteira. Utilizou-se o substrato orgânico, sendo o tipo de recipiente, adubação e manejo das mudas especificados no item 2.3.

O delineamento experimental foi o de blocos ao acaso, em arranjo fatorial $4 \times 6$, constituído de quatro tipos de miniestacas (MA10; MI5; MA5 e MA10i), e seis progênies, com quatro repetições compostas de 10 miniestacas por parcela.

As avaliações feitas na saída da casa de vegetação (30 dias) e da casa de sombra (40 dias) foram quanto à porcentagem de sobrevivência e de raízes observadas na extremidade inferior do tubete. Aos 70 dias de idade, foram avaliados o porcentual de sobrevivência, altura, o diâmetro de colo, número de raízes e a massa seca da parte aérea e da raiz das miniestacas enraizadas. Os dados foram interpretados estatisticamente por meio de análise de variância e teste de média (Teste de Tukey a 5\% de probabilidade), utilizando-se o software Estatística 8.0 (Statsoft Inc. 2008).

\section{RESULTADOS E DISCUSSÃO}

\section{Efeito do substrato e tipo de miniestacas}

Na saída da casa de vegetação e da casa de sombra, não foram observadas diferenças entre as miniestacas cultivadas nos diferentes tipos de substratos quanto à sobrevivência e raiz observada na extremidade inferior do tubete. No entanto, foram observadas diferenças entre as progênies e os tipos de miniestacas quanto às variáveis analisadas (Tabelas 1 e 2).

Na Tabela 1, observa-se que existe diferença entre as progênies para as variáveis analisadas na saída da casa de vegetação e da casa de sombra. Na saída da casa de vegetação, as médias para a sobrevivência variaram de 66,2 \% (progênie P60) a 95,8 \% (progênie P12). Já para raiz observada na extremidade inferior do tubete, as médias variaram

TABELA 1: Sobrevivência (SOB) e raízes observadas na extremidade inferior do tubete (ROEIT) de miniestacas de angico-vermelho (Anadenanthera macrocarpa), na saída da casa de vegetação e casa de sombra, em função da progênie.

TABLE 1: Survival rate (SOB) and roots percentage observed at the bottom of the container (ROEIT) of angico-vermelho (Anadenanthera macrocarpa) mini-cuttings in the greenhouse exit and shade house exit, in function of progeny.

\begin{tabular}{|c|c|c|c|c|c|c|}
\hline \multirow{3}{*}{$\begin{array}{c}\text { Progênie } \\
\text { P1 }\end{array}$} & \multicolumn{2}{|c|}{ Casa de vegetação } & \multicolumn{4}{|c|}{ Casa de sombra } \\
\hline & SOB (\%) & ROEIT (\%) & \multicolumn{2}{|c|}{ SOB (\%) } & \multicolumn{2}{|c|}{ ROEIT (\%) } \\
\hline & $87.5 \mathrm{ab}$ & $27,1 \quad b c$ & 80,2 & $\mathrm{a}$ & 39,6 & $\mathrm{~b}$ \\
\hline P12 & $95.8 \quad$ a & $37,5 \mathrm{ab}$ & 90,6 & $\mathrm{a}$ & 62,0 & $\mathrm{a}$ \\
\hline P17 & $88,0 \quad$ ab & $42,7 \quad$ a & 80,7 & $\mathrm{a}$ & 58,9 & $\mathrm{a}$ \\
\hline P35 & $828 \quad b$ & 45,3 a & 78,7 & $\mathrm{a}$ & 55,2 & $\mathrm{a}$ \\
\hline P45 & $906 \mathrm{ab}$ & 50,5 a & 86,5 & $\mathrm{a}$ & 62,5 & $\mathrm{a}$ \\
\hline $\mathrm{P} 60$ & $662 \mathrm{c}$ & $18,8 \quad \mathrm{c}$ & 58,3 & $\mathrm{~b}$ & 24,5 & $\mathrm{c}$ \\
\hline
\end{tabular}

Em que: Médias seguidas da mesma letra entre as progênies, em uma mesma condição de avaliação, não diferem entre si, pelo teste de Tukey a $5 \%$ de probabilidade 
de 18,8 \% (progênie P60) a 50,5 \% (progênie P45). $\mathrm{Na}$ saída da casa de sombra, as médias para a sobrevivência variaram de 58,3\% (progênie P60) a 90,6 \% (progênie P12), enquanto para raízes observadas na extremidade inferior do tubete, essa variação das médias foi de $24,5 \%$ (progênie P60) a 62,5 \% (progênie P45).

Em relação ao tipo de miniestaca, não houve diferença para o parâmetro sobrevivência na saída da casa de vegetação e da casa de sombra (Tabela 2). No entanto, nas avaliações a pleno sol, constatou-se diferença quanto à sobrevivência das miniestacas apicais $(64,5 \%)$ em relação às miniestacas intermediárias (52\%). Além disso, as miniestacas apicais foram superiores em relação às intermediárias quanto à altura das miniestacas, número de raízes por miniestaca e massa seca da parte aérea. Não foi constatada diferença entre os tipos de miniestacas para peso de massa seca de raiz.

As estacas intermediárias foram superiores às miniestacas apicais apenas quanto ao diâmetro de colo. Esse resultado está correlacionado à variação no diâmetro ao longo do ramo do qual foi coletado o material vegetal para a propagação. Assim, as miniestacas apicais, por estarem na extremidade do ramo, apresentam menor diâmetro inicial do colo, já as miniestacas retiradas da porção intermediária e basal do ramo se apresentam com maior diâmetro inicial de colo (HARTMANN et al., 2011).

De maneira geral, as miniestacas apicais apresentaram médias superiores às intermediárias, sendo que esta diferença pode estar relacionada ao fato de as miniestacas intermediárias apresentarem maior determinação celular, o que pode ter dificultado a capacidade dos tecidos em iniciar o processo de rizogênese, implicando menor competência de retomar as condições meristemáticas (desdiferenciar) e iniciar a formação de raízes adventícias (rediferenciação) (DAVIS et al., 1986). Outro fator que pode estar relacionado a este resultado é a produção de auxinas, que exercem papel crucial no enraizamento adventício (HARTMANN et al., 2011). Além disso, por serem sintetizadas principalmente em regiões de crescimento ativo como primórdios foliares, meristema apical e folhas jovens (RAVEN et al., 2007), as miniestacas apicais tiveram maiores níveis endógenos desse fitorregulador, o que contribuiu para as miniestacas apicais terem médias superiores.

Os resultados das características analisadas a pleno sol permitiram observar a existência de diferença entre as progênies, independentemente

TABELA 2: Sobrevivência (SOB), raízes observadas na extremidade inferior do tubete (ROEIT), enraizamento (ENR), altura, diâmetro de colo (DC), número de raízes, peso da matéria seca da parte aérea (PA) e do sistema radicular (PR) de miniestacas de progênies de seis matrizes selecionadas de Anadenanthera macrocarpa, na saída da casa de vegetação, casa de sombra e pleno sol, em função do tipo de miniestaca (apical e intermediária).

TABLE 2: Survival rate (SOB), roots percentage observed at the bottom of the container (ROEIT), rooting percentage (ENR), height, stem diameter (DC), number of roots and dry mass of shoot (PA) and root system (PR) of six progenies of Anadenanthera macrocarpa in the greenhouse exit, shade house exit and full sunlight area, in function of type of mini-cutting (apical and intermediate).

\begin{tabular}{|c|c|c|c|c|c|c|c|c|c|}
\hline \multirow{2}{*}{$\begin{array}{l}\text { Condiçãao de } \\
\text { avaliação }\end{array}$} & \multirow{2}{*}{ Tipo de miniestaca } & \multirow{2}{*}{ SOB $(\%)$} & \multirow{2}{*}{ ROEIT (\%) } & \multirow{2}{*}{$\operatorname{ENR}(\%)$} & \multirow{2}{*}{ Altura $(\mathrm{cm})$} & \multirow{2}{*}{$\mathrm{DC}(\mathrm{mm})$} & \multirow{2}{*}{$\mathrm{N}^{o}$ raízes } & \multicolumn{2}{|c|}{ Massa seca (g) } \\
\hline & & & & & & & & $\mathrm{PA}$ & PR \\
\hline \multirow{2}{*}{$\begin{array}{l}\text { Casa de vegetação } \\
\quad \text { (40 dias) }\end{array}$} & Apical & 85,3 a & 45,3 a & - & - & - & - & - & - \\
\hline & Intermediária & $85,1 \mathrm{a}$ & $28,7 \mathrm{~b}$ & - & - & - & - & - & - \\
\hline \multirow{2}{*}{$\begin{array}{l}\text { Casa de sombra } \\
\quad \text { (10 dias) }\end{array}$} & Apical & 80,5 a & 56,0 a & - & - & - & - & - & - \\
\hline & Intermediária & $77,8 \mathrm{a}$ & $43,9 \mathrm{~b}$ & - & - & - & - & - & - \\
\hline \multirow{2}{*}{ Pleno sol (30 dias) } & Apical & $65,4 \mathrm{a}$ & - & 65,4 a & $11,0 \mathrm{a}$ & $2,1 \mathrm{~b}$ & $3,7 \mathrm{a}$ & $0,8 \mathrm{a}$ & $6 \mathrm{a}$ \\
\hline & Intermediária & $52,0 \mathrm{~b}$ & - & $52,0 \mathrm{~b}$ & $8,7 \mathrm{~b}$ & $2,5 \mathrm{a}$ & $2 \mathrm{~b}$ & $\begin{array}{c}0,5 \\
\mathrm{~b}\end{array}$ & $4 \mathrm{a}$ \\
\hline
\end{tabular}

Em que: Médias seguidas de uma mesma letra entre tipos de miniestacas e em uma mesma condição de avaliação não diferem entre si, pelo teste de Tukey a 5\% de probabilidade. 
da característica analisada e do tipo de substrato, sendo que, em média, a progênie P12 apresentou resultados superiores às demais progênies (Tabela 3). A diferença entre as progênies com relação às características avaliadas pode ser devida ao genótipo, concordando com Baiyeri e Aba (2005), que também observaram diferentes taxas de sobrevivência na macropropagação de Musa sp. em função do genótipo. No entanto, Tracz et al. (2009) não observaram diferenças entre as progênies quanto ao enraizamento na estaquia de Bactris gasipaes. De acordo com Hartmann et al. (2002), existe grande diferença na capacidade de enraizamento de estacas de plantas entre as progênies e dentro de uma mesma progênie.

Com relação ao substrato (Tabela 3), independentemente da progênie, observa-se que as miniestacas cultivadas na vermiculita apresentaram, em geral, médias superiores em relação às miniestacas cultivadas em composto orgânico quanto à sobrevivência (entre 63,7\% e $72,5 \%$ ), enraizamento (entre $63,7 \%$ e $72,5 \%$ ), altura (entre 9,2 cm e 11,8 cm), diâmetro do colo (entre $2,1 \mathrm{~mm}$ e $2,6 \mathrm{~mm}$ ) e peso de massa seca de raiz (entre $0,3 \mathrm{~g}$ e $0,6 \mathrm{~g}$ ). As miniestacas cultivadas no substrato orgânico apresentaram superioridade em relação às miniestacas cultivadas em vermiculita para número de raízes (entre 3,3 e 5,5). O melhor desempenho das miniestacas no substrato à base de vermiculita pode ser atribuído às propriedades físicas deste substrato, que favorecem a aeração do sistema radicular (GOMES, 2001). Gonçalves e Minami (1994), Fachinello et al. (2005) comentam que a vermiculita é cada vez mais utilizada como substrato para o enraizamento de estacas herbáceas e semilenhosas devido à elevada porosidade e à boa retenção de umidade, características altamente desejáveis no processo de enraizamento adventício.

Além disto, Vazques e Mesquita (2003) afirmam que o uso de vermiculita proporcionou uma melhor distribuição e conformação de raízes de Ixora coceina. O que também foi observado para as miniestacas das progênies de Anadenanthera macrocarpa, através da expressiva massa seca de raiz obtida no substrato à base de vermiculita. Vale ressaltar que o peso da massa seca de raiz está diretamente correlacionado com o volume e quantidade de raízes, fatores primordiais para

TABELA 3: Sobrevivência (SOB), enraizamento (ENR), altura (ALT), diâmetro de colo (DC), número de raízes (NR) e peso da matéria seca da parte aérea (PA) e do sistema radicular (PR) de miniestacas de seis progênies (Prog.) de Anadenanthera macrocarpa aos 80 dias em condições de pleno sol, em função do tipo de substrato (composto orgânico - CO e vermiculita - Verm.).

TABLE 3: Survive rate (SOB), rooting percentage (ENR), height, stem diameter (DC), number of roots (NR) and dry mass of shoot (PA) and root system (PR) of six progenies of Anadenanthera macrocarpa in the full sunlight area at 80 days, in function of substrate (organic substrate $\mathrm{CO}$ and vermiculate- Verm.).

\begin{tabular}{ccccccccc}
\hline \multirow{2}{*}{ Prog. } & Substrato & SOB $(\%)$ & ENR $(\%)$ & ALT $(\mathrm{cm})$ & \multirow{2}{*}{ DC $(\mathrm{mm})$} & \multirow{2}{*}{ NR } & \multicolumn{2}{c}{ Massa seca $(\mathrm{g})$} \\
\hline \multirow{2}{*}{ P1 } & $\mathrm{CO}$ & $46,7 \mathrm{Cb}$ & $46,7 \mathrm{Cb}$ & $8,9 \mathrm{Bb}$ & $2,0 \mathrm{ABb}$ & $4,4 \mathrm{ABCa}$ & $0,3 \mathrm{Aa}$ & $0,3 \mathrm{Ab}$ \\
& Verm. & $63,7 \mathrm{ABa}$ & $63,7 \mathrm{ABa}$ & $9,7 \mathrm{ABa}$ & $2,6 \mathrm{Aa}$ & $3,5 \mathrm{Bb}$ & $0,5 \mathrm{Aa}$ & $0,5 \mathrm{Aa}$ \\
\multirow{2}{*}{ P12 } & $\mathrm{CO}$ & $63,8 \mathrm{ABb}$ & $63,8 \mathrm{ABb}$ & $10,5 \mathrm{ABa}$ & $2,5 \mathrm{Aa}$ & $5,5 \mathrm{Aa}$ & $0,4 \mathrm{Aa}$ & $0,2 \mathrm{Ab}$ \\
& Verm. & $72,5 \mathrm{Aa}$ & $72,5 \mathrm{Aa}$ & $10,8 \mathrm{ABa}$ & $2,6 \mathrm{Aa}$ & $4,1 \mathrm{Bb}$ & $0,6 \mathrm{Aa}$ & $0,6 \mathrm{Aa}$ \\
\multirow{2}{*}{ P17 } & $\mathrm{CO}$ & $78,8 \mathrm{Aa}$ & $78,8 \mathrm{Aa}$ & $7,8 \mathrm{Bb}$ & $1,9 \mathrm{Ba}$ & $3,3 \mathrm{Ca}$ & $0,4 \mathrm{Aa}$ & $0,3 \mathrm{Ab}$ \\
& Verm. & $62,5 \mathrm{Ab}$ & $62,5 \mathrm{Ab}$ & $9,2 \mathrm{Ba}$ & $2,1 \mathrm{Ba}$ & $3,7 \mathrm{Ba}$ & $0,6 \mathrm{Aa}$ & $0,6 \mathrm{Aa}$ \\
\multirow{2}{*}{ P35 } & $\mathrm{CO}$ & $42,5 \mathrm{Bb}$ & $42,5 \mathrm{Bb}$ & $9,4 \mathrm{Bb}$ & $1,8 \mathrm{Cb}$ & $3,7 \mathrm{BCb}$ & $0,4 \mathrm{Aa}$ & $0,2 \mathrm{Ab}$ \\
& Verm. & $67,9 \mathrm{Aa}$ & $67,9 \mathrm{Aa}$ & $11,8 \mathrm{Aa}$ & $2,2 \mathrm{Ba}$ & $6,0 \mathrm{Aa}$ & $0,4 \mathrm{Aa}$ & $0,5 \mathrm{Aa}$ \\
P45 & $\mathrm{CO}$ & $49,2 \mathrm{Bb}$ & $49,2 \mathrm{Bb}$ & $11,3 \mathrm{Aa}$ & $1,9 \mathrm{Bb}$ & $5,1 \mathrm{ABa}$ & $0,3 \mathrm{Aa}$ & $0,2 \mathrm{Ab}$ \\
& Verm. & $68,8 \mathrm{Aa}$ & $68,8 \mathrm{Aa}$ & $9,9 \mathrm{ABb}$ & $2,4 \mathrm{ABa}$ & $4,1 \mathrm{Bb}$ & $0,5 \mathrm{Aa}$ & $0,3 \mathrm{Ba}$ \\
\multirow{2}{*}{ P60 } & $\mathrm{CO}$ & $62,5 \mathrm{ABa}$ & $62,5 \mathrm{ABa}$ & $9,8 \mathrm{ABa}$ & $2,1 \mathrm{ABb}$ & $5,3 \mathrm{Aa}$ & $0,4 \mathrm{Aa}$ & $0,4 \mathrm{Aa}$ \\
& Verm. & $64,7 \mathrm{ABa}$ & $64,7 \mathrm{ABa}$ & $9,7 \mathrm{ABa}$ & $2,5 \mathrm{Aa}$ & $4,0 \mathrm{Ba}$ & $0,4 \mathrm{Aa}$ & $0,4 \mathrm{ABa}$ \\
\hline
\end{tabular}

Em que: Médias seguidas de uma mesma letra maiúscula, entre as progênies e um mesmo tipo de substrato, e as seguidas de uma mesma letra minúscula dentro de cada progênie não diferem entre si, pelo teste de Tukey a $5 \%$ de probabilidade. 
o melhor desenvolvimento das mudas após o transplantio a campo. Silva et al. (2010), avaliando a eficiência da técnica de miniestaquia para a propagação clonal de Calophyllum brasiliense, observaram que o substrato à base de vermiculita proporcionou redução no tempo de permanência das miniestacas em casa de vegetação. Tracz et al. (2009) observaram na propagação vegetativa de Bactris gasipaes que os substratos contendo vermiculita em sua composição apresentaram médias de sobrevivência e enraizamento das estacas superiores àquelas cultivadas nos substratos orgânicos puros.

Entretanto, Castro (2011) encontrou para estacas de Piptadenia gonoacantha as maiores médias de sobrevivência e enraizamento quando cultivadas no substrato composto por material orgânico, sendo que as miniestacas cultivadas em vermiculita obtiveram menores médias. Este fato pode estar relacionado ao maior tempo de permanência em casa de vegetação (60 dias para o referido experimento) que, aliado à alta retenção de água pela vermiculita, pode ter proporcionado maior umidade do substrato, dificultando o enraizamento e a sobrevivência das estacas.

Portanto, o substrato tem papel fundamental no enraizamento adventício, não tendo apenas a função de suporte, devendo também apresentar características que favoreçam o crescimento radicular. Contudo, o sucesso na propagação via miniestaquia não é determinado apenas pelo substrato utilizado, mas depende de diversos outros fatores, tais como: controle das condições ambientais no ambiente de propagação, tipo de estacas, nutrição das minicepas e resposta do material genético ao enraizamento adventício.

\section{Efeito da redução foliar e do tipo de miniestacas}

As variáveis analisadas na saída da casa de vegetação e da casa de sombra não revelaram interação entre os fatores tipo de miniestacas e progênies, havendo significância $(F<0,05)$ somente dos fatores independentes. Entretanto, para as variáveis analisadas a pleno sol, foi observada interação significativa $(F<0,05)$ entre tipo de miniestacas e progênies.

Na Tabela 4 são apresentados os resultados

TABELA 4: Sobrevivência (SOB) e raízes observadas na extremidade inferior do tubete (ROEIT) de miniestacas de Anadenanthera macrocarpa, na saída da casa de vegetação e da casa de sombra, em função da progênie e do tipo de miniestaca (MA10; MI5; MA5; MA10i).

TABLE 4: $\quad$ Survival rate (SOB) and roots percentage observed at the bottom of the container (ROEIT) of angico-vermelho (Anadenanthera macrocarpa) mini-cuttings in the greenhouse exit and shade house exit, in function of progeny and type of mini-cutting (MA10; MI5; MA5; MA10i).

\begin{tabular}{|c|c|c|c|c|c|}
\hline & & \multicolumn{2}{|c|}{ Casa de vegetação } & \multicolumn{2}{|c|}{ Casa de sombra } \\
\hline & & SOB $(\%)$ & ROEIT (\%) & SOB $(\%)$ & ROEIT (\%) \\
\hline \multirow{6}{*}{ Progênie } & $\mathrm{P} 1$ & 92,5 a & 54,4 a & 91,3 a & 72,5 a \\
\hline & P12 & 99,4 a & 71,9 a & 97,5 a & 86,9 a \\
\hline & P17 & 92,5 a & $70,0 \quad \mathrm{a}$ & 90,6 a & 74,4 a \\
\hline & P35 & 95,6 a & 81,3 a & $95,0 \quad \mathrm{a}$ & 86,3 a \\
\hline & P45 & 97,5 a & 73,1 a & 90,6 a & 76,9 a \\
\hline & P60 & 95,6 a & $31,3 \quad b$ & 89,4 a & $42,5 \mathrm{~b}$ \\
\hline \multirow{4}{*}{ Tipo de miniestaca } & MA10 & 95,8 a & 68,3 a & 90,8 a & $75,8 \mathrm{ab}$ \\
\hline & MI5 & 96,3 a & $43,3 \quad b$ & 91,7 a & 59,6 c \\
\hline & MA5 & 93,8 a & $63,3 \mathrm{ab}$ & 90,0 a & 69,6 bc \\
\hline & MA10i & 96,3 a & 79,6 a & 97,1 a & 87,9 a \\
\hline
\end{tabular}

Em que: Médias seguidas de uma mesma letra entre progênies ou tipo de miniestacas e em uma mesma condição de avaliação não diferem entre si, pelo teste de Tukey a 5\% de probabilidade. MA10: apical com $10 \mathrm{~cm}$ de tamanho, contendo de um a dois pares de folhas, reduzidas a 25\% de seu tamanho original; MI5: intermediária com $5 \mathrm{~cm}$ de tamanho, contendo de um a dois pares de folhas, reduzidas a $25 \%$ de seu tamanho original; MA5 apical com $5 \mathrm{~cm}$ de tamanho, contendo de um a dois pares de folhas, reduzidas a 25\% de seu tamanho original e MA10i: apical com 10 $\mathrm{cm}$ de tamanho e com a folha inteira. 
de sobrevivência e de raízes observadas na extremidade inferior do tubete. Avaliando a sobrevivência, constata-se que não houve diferença entre os tratamentos quanto a esta variável na saída da casa de vegetação e da casa de sombra. Em relação à porcentagem de raízes observadas na extremidade inferior do tubete entre as progênies, observa-se que a progênie da matriz 60 apresentou média inferior ( $31,3 \%$ e $42,5 \%$ na saída da casa de vegetação e da casa de sombra, respectivamente) às demais.

Observou-se quanto ao tipo de miniestacas que as apicais de $10 \mathrm{~cm}$ de comprimento com folha inteira e as apicais com $10 \mathrm{~cm}$ de comprimento e folha cortada $25 \%$ do seu tamanho original foram superiores às demais para a porcentagem de raízes observadas na extremidade inferior do tubete na saída da casa de vegetação e da casa de sombra (Tabela 4). Este resultado pode estar relacionado com a lignificação dos tecidos, já que as miniestacas com $5 \mathrm{~cm}$ estão muito tenras, necessitando de maior controle das condições ambientais durante o enraizamento, para evitar a desidratação dos tecidos (XAVIER et al., 2009).

$\mathrm{Na}$ condição de pleno sol, observa-se diferença entre as progênies dentro de cada tipo de miniestaca (Tabela 5) e, independentemente da variável analisada e do tipo de miniestaca, em geral a progênie $\mathrm{P} 12$ apresentou médias superiores às demais. Analisando o tipo de miniestacas dentro de cada progênie, observa-se para a variável altura que, independentemente da progênie, as miniestacas apicais com $10 \mathrm{~cm}$ de comprimento e com a folha inteira e as apicais com $10 \mathrm{~cm}$ de comprimento, contendo de um a dois pares de folhas, reduzidas a $25 \%$ de seu tamanho original, foram superiores às demais.

As diferenças observadas entre as progênies podem ser explicadas pela variabilidade genética. Segundo Xavier et al. (2009), as variações fenotípicas entre plantas propagadas via assexuada resultam da interação entre os efeitos genotípicos, efeitos ambientais e da interação "genótipo x ambiente". Como no experimento as progênies estavam todas sob uma mesma condição ambiental, possivelmente as variações observadas nas características avaliadas tenham advindo da diferença entre os genótipos ou em função das diferenças entre ritmos endógenos da planta relacionados a fatores fisiológicos e morfológicos (MANKESSI et al., 2009).

A miniestaca apical com $10 \mathrm{~cm}$ de comprimento e com a folha inteira apresentou maiores médias, independentemente da progênie, para os parâmetros sobrevivência (entre $63,3 \%$ e $100 \%$ ), enraizamento (entre $63,3 \%$ e $100 \%$ ), número de raízes (entre 5,2 e 8,1 ) e massa seca da parte aérea (entre $0,2 \mathrm{~g}$ e $0,5 \mathrm{~g}$ ) e da raiz (entre 0,4 e 0,9 ) (Tabela 5). Para o diâmetro de colo, as miniestacas intermediárias com $5 \mathrm{~cm}$ de comprimento, contendo de um a dois pares de folhas, reduzidas a $25 \%$ de seu tamanho original e a apical com $10 \mathrm{~cm}$ de comprimento e com a folha inteira, apresentaram médias superiores aos demais tratamentos. Portanto, verificou-se, com relação ao tipo de miniestaca, que, independentemente da condição de avaliação e da variável estudada, a miniestaca apical com $10 \mathrm{~cm}$ de comprimento e com a folha inteira apresentou médias superiores aos demais tipos de miniestacas. Desta forma, é recomendável que não se reduza a área foliar para miniestacas de Anadenanthera macrocarpa, pois estacas com a folha inteira permitiram um desenvolvimento semelhante ou superior às miniestacas com folha reduzida, além de não causar estresse nas miniestacas em virtude do corte foliar.

A superioridade das miniestacas apicais com $10 \mathrm{~cm}$ de comprimento e folha inteira, principalmente com relação ao enraizamento, pode estar relacionada com a produção de substâncias favoráveis ao enraizamento. De acordo com Hartmann et al. (2002), a presença de $100 \%$ da área foliar ou mesmo de folhas cortadas é uma condição prévia para a produção de auxinas, cofatores de enraizamento e fotoassimilados, indispensáveis ao crescimento de novas estruturas, que são translocados para a base da miniestaca, favorecendo a rizogênese. Segundo estes autores, diferentes materiais genéticos podem ter diferentes respostas ao enraizamento em função da presença de folhas inteiras ou parte delas.

Por outro lado, as médias inferiores para as miniestacas intermediárias quanto às características avaliadas, podem ser devidas à síntese de auxinas indutoras da rizogênese ser feita principalmente em regiões de crescimento ativo, como gemas terminais e primórdios foliares, o que contribuiria para a elevação dos níveis endógenos desse fitorregulador nas estacas apicais, refletindo-se em maior potencial de enraizamento (XAVIER et al., 2003, HARTMANN et al., 2002; BORGES et al., 2011).

Outro fator que pode ter influência nas características avaliadas é a maior lignificação dos tecidos das estacas intermediárias. Segundo Hartmann et al. (2002), a lignificação dos tecidos 
TABELA 5: Sobrevivência (SOB), enraizamento (ENR), altura (ALT), diâmetro de colo (DC), número de raízes (NR) e peso da matéria seca da parte aérea (MSPA) e da raiz (MSPR), de seis progênies (P) de Anadenanthera macrocarpa, em condições de pleno sol, aos 70 dias, em função do tipo de miniestaca (MA10; MI5; MA5; MA10i).

TABLE 5: Survive rate (SOB), rooting percentage (ENR), height (ALT), stem diameter (DC), number of roots (NR) and dry mass of shoot (MSPA) and root system (MSPR) of six progenies of Anadenanthera macrocarpa in the full sunlight area at 70 days, in function of type of minicutting (MA10; MI5; MA5; MA10i).

\begin{tabular}{|c|c|c|c|c|c|c|c|c|}
\hline \multirow{2}{*}{ Prog. } & \multirow{2}{*}{ Tipo } & \multirow{2}{*}{ SOB (\%) } & \multirow{2}{*}{ ENR (\%) } & \multirow{2}{*}{ ALT (cm) } & \multirow{2}{*}{$\mathrm{DC}(\mathrm{mm})$} & \multirow{2}{*}{ NR } & \multicolumn{2}{|c|}{ Massa seca (g) } \\
\hline & & & & & & & $\mathrm{PA}$ & PR \\
\hline \multirow{4}{*}{$\mathrm{P} 1$} & MA10 & $76,7 \mathrm{Ba}$ & $76,7 \mathrm{Ba}$ & $12,8 \mathrm{Aba}$ & $2,3 \mathrm{ABbc}$ & $3,8 \mathrm{Ab}$ & $0,2 \mathrm{Bb}$ & $0,3 \mathrm{Ab}$ \\
\hline & MI5 & $65,0 \mathrm{Bab}$ & $65,0 \mathrm{Bab}$ & $8,4 \mathrm{Ab}$ & 2,6 Aab & $2,5 \mathrm{Bb}$ & $0,3 \mathrm{ABa}$ & $0,2 \mathrm{Abc}$ \\
\hline & MA5 & $53,3 \mathrm{Cb}$ & $53,3 \mathrm{Cb}$ & $8,8 \mathrm{ABb}$ & $1,9 \mathrm{Ac}$ & $3,3 \mathrm{ABb}$ & $0,2 \mathrm{Bb}$ & $0,2 \mathrm{Cc}$ \\
\hline & MA10i & $73,3 \mathrm{Ba}$ & $73,3 \mathrm{Ba}$ & $12,9 \mathrm{Aa}$ & 2,7 Aba & $6,5 \mathrm{ABa}$ & $0,2 \mathrm{Cb}$ & $0,7 \mathrm{ABa}$ \\
\hline \multirow{4}{*}{ P12 } & MA10 & $95,0 \mathrm{Aa}$ & $95,0 \mathrm{Aa}$ & $13,1 \mathrm{ABa}$ & 2,4 Aab & $4,9 \mathrm{Ab}$ & $0,4 \mathrm{Aab}$ & $0,4 \mathrm{Ab}$ \\
\hline & MI5 & $86,7 \mathrm{Ab}$ & $86,7 \mathrm{Ab}$ & $9,1 \mathrm{Ac}$ & $2,7 \mathrm{Aa}$ & $2,9 \mathrm{ABc}$ & $0,4 \mathrm{Aab}$ & $0,3 \mathrm{Ac}$ \\
\hline & MA5 & $83,3 \mathrm{Ab}$ & $83,3 \mathrm{Ab}$ & $10,0 \mathrm{Ab}$ & $2,3 \mathrm{Ab}$ & $4,2 \mathrm{Abc}$ & $0,3 \mathrm{Ab}$ & $0,3 \mathrm{Ac}$ \\
\hline & MA10i & $100,0 \mathrm{Aa}$ & $100,0 \mathrm{Aa}$ & $13,9 \mathrm{Aa}$ & $2,8 \mathrm{Aa}$ & 7,2 Aba & $0,5 \mathrm{Aa}$ & $0,9 \mathrm{Aa}$ \\
\hline \multirow{4}{*}{ P17 } & MA10 & 90,0 Аа & $90,0 \mathrm{Aa}$ & $13,3 \mathrm{Aba}$ & $2,3 \mathrm{ABb}$ & $4,1 \mathrm{Ab}$ & $0,3 \mathrm{ABa}$ & 0,4 Aab \\
\hline & MI5 & $50,0 \mathrm{Cc}$ & $50,0 \mathrm{Cc}$ & $8,1 \mathrm{Ab}$ & $2,7 \mathrm{Aa}$ & $2,4 \mathrm{Bc}$ & $0,3 \mathrm{ABa}$ & $0,2 \mathrm{Ac}$ \\
\hline & MA5 & $50,0 \mathrm{Cc}$ & $50,0 \mathrm{Cc}$ & $8,9 \mathrm{ABb}$ & $2,1 \mathrm{Ab}$ & 2,9 Bbc & $0,2 \mathrm{Bb}$ & $0,2 \mathrm{BCc}$ \\
\hline & MA10i & $76,7 \mathrm{Bb}$ & $76,7 \mathrm{Bb}$ & $12,9 \mathrm{Aa}$ & $2,3 \mathrm{Bb}$ & $5,7 \mathrm{Ba}$ & $0,3 \mathrm{Ba}$ & $0,4 \mathrm{Ba}$ \\
\hline \multirow{4}{*}{ P35 } & MA10 & 83,3 Аа & 83,3 Aa & $14,1 \mathrm{Aa}$ & $2,4 \mathrm{Ab}$ & $4,6 \mathrm{Ab}$ & $0,3 \mathrm{ABa}$ & $0,4 \mathrm{Ab}$ \\
\hline & MI5 & $73,3 \mathrm{ABb}$ & $73,3 \mathrm{ABb}$ & $8,5 \mathrm{Ab}$ & 2,5 Aab & $4,2 \mathrm{Ab}$ & $0,2 \mathrm{Bb}$ & $0,2 \mathrm{Ac}$ \\
\hline & MA5 & $63,3 \mathrm{Bb}$ & $63,3 \mathrm{Bb}$ & $8,8 \mathrm{ABb}$ & $1,9 \mathrm{Ac}$ & $3,6 \mathrm{ABb}$ & $0,2 \mathrm{Bb}$ & $0,2 \mathrm{BCc}$ \\
\hline & MA10i & $100,0 \mathrm{Aa}$ & $100,0 \mathrm{Aa}$ & $13,9 \mathrm{Aa}$ & $2,7 \mathrm{ABa}$ & 8,1 Aa & $0,3 \mathrm{Ba}$ & $0,8 \mathrm{Aa}$ \\
\hline \multirow{4}{*}{ P45 } & MA10 & $83,3 \mathrm{Aa}$ & $83,3 \mathrm{Aa}$ & $13,1 \mathrm{ABa}$ & $2,2 \mathrm{ABab}$ & $3,8 \mathrm{Ab}$ & $0,3 \mathrm{ABb}$ & $0,4 \mathrm{Aab}$ \\
\hline & MI5 & $63,3 \mathrm{Ba}$ & $63,3 \mathrm{Ba}$ & $8,5 \mathrm{Ab}$ & 2,5 Aab & $3,3 \mathrm{ABb}$ & $0,2 \mathrm{Bc}$ & $0,3 \mathrm{Ab}$ \\
\hline & MA5 & $70,0 \mathrm{ABab}$ & $70,0 \mathrm{ABab}$ & $9,7 \mathrm{Ab}$ & $2,1 \mathrm{Ab}$ & $3,9 \mathrm{ABb}$ & $0,3 \mathrm{Ab}$ & 0,3 ABab \\
\hline & MA10i & $86,7 \mathrm{ABa}$ & $86,7 \mathrm{ABa}$ & $14,1 \mathrm{Aa}$ & $2,7 \mathrm{ABa}$ & 7,5 Aba & $0,5 \mathrm{Aa}$ & $0,6 \mathrm{ABa}$ \\
\hline \multirow{4}{*}{ P60 } & MA10 & $53,3 \mathrm{Cab}$ & $53,3 \mathrm{Cab}$ & $12,5 \mathrm{Ba}$ & $2,1 \mathrm{Ba}$ & 4,2 Aab & $0,3 \mathrm{ABa}$ & $0,4 \mathrm{Aa}$ \\
\hline & MI5 & $46,7 \mathrm{Cb}$ & $46,7 \mathrm{Cb}$ & $9,1 \mathrm{Ab}$ & $2,5 \mathrm{Aa}$ & $3,5 \mathrm{ABb}$ & $0,2 \mathrm{Bb}$ & $0,2 \mathrm{Ab}$ \\
\hline & MA5 & $45,0 \mathrm{Cb}$ & $45,0 \mathrm{Cb}$ & $8,3 \mathrm{Bb}$ & $2,1 \mathrm{Aa}$ & $2,8 \mathrm{Bb}$ & $0,2 \mathrm{Bb}$ & $0,2 \mathrm{BCb}$ \\
\hline & MA10i & $63,3 \mathrm{Ca}$ & $63,3 \mathrm{Ca}$ & $13,2 \mathrm{Aa}$ & $2,5 \mathrm{ABa}$ & $5,6 \mathrm{Ba}$ & $0,3 \mathrm{Ba}$ & $0,4 \mathrm{Ba}$ \\
\hline
\end{tabular}

Em que: Médias seguidas de uma mesma letra maiúscula, entre as progênies e um mesmo tipo de miniestaca, e as seguidas de uma mesma letra minúscula dentro de cada progênie não diferem entre si, pelo teste de Tukey a $5 \%$ de probabilidade. MA10: apical com $10 \mathrm{~cm}$ de tamanho, contendo de um a dois pares de folhas, reduzidas a $25 \%$ de seu tamanho original; MI5: intermediária com $5 \mathrm{~cm}$ de tamanho, contendo de um a dois pares de folhas, reduzidas a $25 \%$ de seu tamanho original; MA5: apical com $5 \mathrm{~cm}$ de tamanho, contendo de um a dois pares de folhas, reduzidas a $25 \%$ de seu tamanho original e MA10i: apical com $10 \mathrm{~cm}$ de tamanho e com a folha inteira.

pode funcionar como barreira física para emissão de raízes, além de estar relacionada, negativamente, com o nível de auxina, visto que a peroxidase, enzima responsável pela síntese de lignina, degrada a auxina.

Resultados semelhantes aos encontrados neste trabalho foram observados por Xavier et al. (2003) avaliando o enraizamento de cinco tipos de miniestaca - caulinar, caulinar apical, caulinar intermediária, caulinar apical desfolhada e foliar na propagação vegetativa de cedro-rosa (Cedrela fissilis) por miniestaquia. Estes autores observaram que o enraizamento da miniestaca caulinar foi, em média, superior aos demais tipos de miniestacas para as características avaliadas. Para o gênero Eucalyptus spp., também se tem observado que 
as estacas apicais, em geral, apresentam maior predisposição ao enraizamento em comparação com as intermediárias (BORGES et al., 2011; OLIVEIRA, 2011).

Além disso, estaca com folha inteira reduz o risco de contaminação por microrganismos em função da não existência de lesões nas folhas, bem como proporciona aumento no rendimento do trabalho operacional de preparo das miniestacas. Resultado semelhante foi encontrado por Santana et al. (2010) ao avaliarem o efeito da redução da área foliar na produção de mudas de oito clones de eucalipto, demonstrando que o nível de $0 \%$ de redução foliar pode ser adotado para a maioria dos clones avaliados.

Segundo Santana et al. (2010), a redução da área foliar tem sido utilizada como premissa para minimizar a incidência de patógenos, aumentar a eficiência da irrigação em virtude do efeito guardachuva, evitar a seca das miniestacas por transpiração excessiva e diminuir a flexão das miniestacas em virtude do peso da lâmina de água sobre a folha. Entretanto, estes problemas não foram observados no presente trabalho, devido à espécie possuir folhas recompostas, tornando viável a utilização de miniestacas apicais com $100 \%$ da área foliar.

De acordo com os percentuais de enraizamento obtidos pelas miniestacas apicais, a miniestaquia de Anadenanthera macrocarpa, a partir de material de origem seminal, indica ser tecnicamente viável, tornando-se alternativa para produção de mudas dessa espécie durante todo o ano, principalmente nas situações em que a semente for insumo limitante.

\section{CONCLUSÕES}

Houve diferença de resposta ao enraizamento para miniestacas cultivadas nos tipos de substratos e tipos de miniestacas, quanto às variáveis analisadas, entre as progênies de Anadenanthera macrocarpa estudadas.

A miniestaca apical cultivada no substrato à base de vermiculita proporcionou maiores médias para o enraizamento adventício de progênies de Anadenanthera macrocarpa por miniestaquia.

A miniestaca apical com $10 \mathrm{~cm}$ de comprimento e com folha inteira mostrou-se mais adequada à propagação vegetativa de angicovermelho (Anadenanthera macrocarpa) por miniestaquia, a partir de material seminal.

\section{AGRADECIMENTOS}

Os autores agradecem ao $\mathrm{CNPq}$ (Conselho Nacional de Desenvolvimento Científico e Tecnológico), pela concessão de bolsas de estudo, e à Sociedade de Investigação Florestal (SIF), pela disponibilização de material seminal de angicovermelho.

\section{REFERÊNCIAS BIBLIOGRÁFICAS}

ASSIS, T. A.; TEIXEIRA, S. L. Enraizamento de plantas lenhosas. In: TORRES, A.C. et al. (Ed.). Cultura de tecidos e transformação genética de plantas. Brasília: Embrapa, 1998. v. 1, p. 261-297.

BAIYERI, K. P.; ABA. S. C. Response of Musa species to macropropagation. I. Genetic and initiation media effects on number, quality and survival of plants at nursery and early nursery stages. African Journal of Biotecnology, South Africa, v. 4, n. 3, p. 223-228, 2005.

BORGES, S. R. et al. Enraizamento de miniestacas de clones híbridos de Eucalyptus globulus. Revista Árvore, Viçosa, v. 35, n. 3, p. 425-434. 2011.

CARVALHO, P.E.R. Espécies arbóreas brasileiras. Colombo: Embrapa-CNPF; Brasilia, D.F.: Embrapa-SPI, 2003. 1039p.

CASTRO, W. H. propagação vegetativa do jequitibá-rosa (Cariniana estrellensis (Raddi) Kuntze) e do pau-jacaré (Piptadenia gonoacantha (Mart.) Macbr.) por estaquia. 2011. 72 f. Dissertação (Mestrado em Ciência Florestal) - Universidade Federal de Viçosa, Viçosa, MG, 2011.

CUNHA, A. C. M. C. M. da; WENDLING, I.; SOUZA JÚNIOR, L. Miniestaquia em sistema de hidroponia e em tubetes de corticeira-domato. Ciência Florestal, Santa Maria, v. 18, n. 1, p. 85-92, 2008.

DAVIS, T.D.; HAISSIG, B.E.; SANKHLA, N. Adventitious root formation in cuttings. Oregon: Dioscorides Press, 1986. 315 p.

FACHINELLO, J. C.; HOFFMANN, A.; NACHTIGAL, J. C. Propagação de plantas frutíferas. Brasília. Embrapa: Informação Tecnológica. 2005. $221 \mathrm{p}$.

FERREIRA, B. G. A. et al. Miniestaquia de Sapium glandulatum (Vell.) Pax com o uso de ácido indol butírico e ácido naftaleno acético. Ciência Florestal, Santa Maria, v. 20, n. 1, p. 19-31, 2010. 
GOMES, J. M. Parâmetros morfológicos na avaliação da qualidade de mudas de Eucalyptus grandis, produzidas em diferentes tamanhos de tubetes e de dosagens de NPK. 2001. 166f. Tese (Doutorado em Engenharia Florestal) -, Universidade Federal de Viçosa, Viçosa, MG, 2001.

GONÇALVES, A. L.; MINAMI, K. Efeito de substrato artificial no enraizamento de estacas de calanchoe (Kalanchoe x blossfeldiana cv. Singapur, Crassulaceae). Scientia Agricola, Piracicaba, v. 51, n. 2, 1994.

HARTMANN, H. T. e al. Plant propagation: principles and practices. 8 ed. New Jersey:: Prentice Hall, 2011. 915p.

MANKESSI, F. et al. In vitro rooting of genetically related Eucalyptus urophylla $\times$ Eucalyptus grandis clones in relation to the time spent in culture. Trees, Berlin, v. 23, n.5, p: 931-940, 2009.

OLIVEIRA, L. S. de. Micropropagação, microestaquia e miniestaquia de clones híbridos de Eucalyptus globulus. 2011. 71f. Dissertação (Mestrado em Ciência Florestal) - Universidade Federal de Viçosa, Viçosa, MG, 2011.

SANTANA, R. C. et al. Influence of leaf area reduction on clonal production of Eucalyptus seedling. Cerne, Lavras, v. 16, n. 3, p. 251-257, 2010.

SILVA, R. L. et al. Propagação clonal de guanandi (Calophyllum brasiliense) por miniestaquia. Agronomía Costarricense, San José, v. 34, n. 1, p. 99-104, 2010.
SOUZA, J. C. A. V. de et al. Propagação vegetativa de cedro-australiano (Toona ciliata M. Roemer) por miniestaquia. Revista Árvore, Viçosa, v. 33, n. 2, p. 205-213, 2009.

TRACZ, A. L. et al. Enraizamento de perfilhos de pupunheira (Bactris gasipaes). Pesquisa Florestal Brasileira, Colombo, n. 58, p. 67-73, 2009.

VAZQUES, G. H.; MESQUITA, K. A. C. 2003. Avaliação de diferentes substratos e doses de hormônio no enraizamento de estacas de ixora (Ixora coccínea L. inn compacta). In: CONGRESSO BRASILEIRO DE FLORICULTURA E PLANTAS ORNAMENTAIS E $1^{\circ}$ CONGRESSO BRASILEIRO DE CULTURA DE TECIDOS DE PLANTAS, 14., 2003, Lavras. Anais... Lavras: UFLA, 2001. p. 101.

WENDLING, I.; DUTRA, L. F.; GROSSI, F. Produção e sobrevivência de miniestacas e minicepas de erva-mate cultivadas em sistema semihidropônico. Pesquisa Agropecuária Brasileira, Brasília, v.42, n.2, p.289-292, 2007.

XAVIER, A.; SANTOS, G. A. dos; OLIVEIRA, M. L. de. Enraizamento de miniestaca caulinar e foliar na propagação vegetativa de cedro-rosa (Cedrela fissilis Vell.). Revista Árvore, Viçosa, v. 27, n. 3, p. 351-356, 2003.

XAVIER, A.; WENDLING, I.; SILVA, R. L. Silvicultura clonal - Princípios e Técnicas. Viçosa: UFV, 2009. 272p.

RAVEN, P. H.; EVERT, R. F.; EICHHORN, S. E. Biologia vegetal. 7 ed. Rio de Janeiro: Guanabara Koogan, 2007. 830 p. (Tradução). 